
\title{
25 Research Suare \\ Clinical features of B. 1.617.2 (delta) variant concern (VOC): first case in Iraq
}

\section{Rawand Essa}

Ph.D. in Cardiothoracic and Vascular surgery, Lecturer in the University of Raparin, College of Nursing, Department of Adult Nursing, Rania, Sulaimani, Kurdistan-region,Iraq

\section{Sirwan Ahmed ( $\square$ sirwan.ahmed1989@gmail.com)}

RN, DIN, BSN, In science of Nursing, University of Raparin, College of Nursing, Main Street, Rania, 46012, Kurdistan region-Iraq https://orcid.org/0000-0002-8361-0546

\section{Dunya Bapir}

Department of Medical Laboratory, College of Science, University of Raparin, Kurdistan-region, Iraq

\section{Chawan Abubakr}

Department of critical care nursing, College of Nursing, Urmia University of Medical Science, Iran

\section{Shero Rasul}

Rania Teaching Hospital, Rania, Sulaimani, Kurdistan-region, Iraq

\section{Awat Khdir}

Rania Medical City private hospital, Rania, Sulaimani, kurdistan-region, Iraq

\section{Case Report}

Keywords: Variant concern (VOC), B.1.617.2, Delta variant, COVID-19, SARS-CoV-2, Effectiveness COVID19 vaccines, Clinical features delta variant (VOC)

Posted Date: August 18th, 2021

DOl: https://doi.org/10.21203/rs.3.rs-775840/v3

License: (c) (1) This work is licensed under a Creative Commons Attribution 4.0 International License. Read Full License

Version of Record: A version of this preprint was published at Annals of Medicine and Surgery on September 4th, 2021. See the published version at https://doi.org/10.1016/j.amsu.2021.102814. 


\section{Abstract}

Since the initial report of the severe acute respiratory syndrome (SARS CoV-2) in Wuhan, China, in 2019, the virus has constantly mutated, resulting in the appearance of novel variants. In December 2020, the B.1.617.2 (delta) variant concern (VOC) was first reported in India, and rapidly spread around the globe, is now the main brand in the United Kingdom, and it has grown dramatically. Here we present the clinical features and laboratory findings of the first case of B. 1.617.2 (delta) variant concern (VOC) in Iraq. A 6year-old female child presented with severe abdominal pain, headache, severe vomiting, and diarrhea, runny nose, alerted mental status, loss of appetite, and fever. The patient was diagnosed with COVID-19 delta variant B.1.617.2 by RT-PCR. The patient was treated by administration of glucose saline $4 \%$ for 3 days, ceftriaxone vial $1 \mathrm{mg}$ every $12 \mathrm{~h}$ for 6 days, and an acetaminophen bottle on a need to prevent fever followed by a Flagyl bottle every $24 \mathrm{~h}$ for 3 days. Vaccination and prevention the spread of the virus and against it are important preventive approaches for delta variant. Sore throat, runny nose, headache, and vomiting, diarrhea are the major clinical features of the delta variant. This was followed by an elevation of the leukocyte WBC, and blood platelets. To reduce the impact of new delta variant B.1.617.2 infection; handwashing, wearing a double mask, avoiding crowded and closed settings, social distancing, lockdown, and ensuring good ventilation are major significant options against this variant.

\section{Introduction}

Since the initial report of the severe acute respiratory syndrome (SARS CoV-2) in Wuhan, China in 2019, the virus has constantly mutated, resulting in the appearance of novel variants [1,2]. SARS-CoV-2 has caused millions of deaths globally, producing thousands of variants spreading around the world [3]. The B.1.617.2 (delta) variant concern (VOC) was first reported in India in December 2020 and rapidly spread around the globe, and is now the main brand in the United Kingdom, France, Japan, and increasing dramatically [4-6]. The main symptoms of infection with the delta variant are sore throat, headaches, and runny nose. The WHO warns that the Delta variant is quickly becoming the main strain of SARS-CoV-2 worldwide, due to its higher transmissibility and mortality rate [7-9]. Globally, numerous treatment options have been examined for hospitalized patients with COVID-19 (e.g., antiviral agents [1012], antimalarial drugs [13], glucocorticoids [10,14], convalescent plasma [15,16], and immunomodulators [10,17-20]. Additionally, herbal treatment medicine was used against delta variant B.1.617.2 [21]. The world's largest purchase of the AstraZeneca vaccine, the efficacy of this vaccine against the delta variant is only \%10.4 [22]. For this reason, the transmissibility of this variant was higher than of previous variants and, distressing. In Iraq, particularly in Kurdistan-region populations have a lack of information about this variant. Additionally, vaccine hesitancy, political, financial, and economic issues are major reasons to get vaccines. To date, numerous variants have been reported in different countries.

To the best of our knowledge, this is the first case of delta variant coronavirus in Iraq. The current study aims to present clinical features and laboratory findings of the first case delta variant B.1.617.2 in Iraq. The current paper has been written in the line with SCARE guidelines [23]. 


\section{Case Presentation}

\subsection{Patient Information}

On July 20, 2021, a 6-year-old female, was admitted to the Hajiawa General Hospital (HGH) government hospital in the Kurdistan region, Iraq, she presented with severe abdominal pain, headache, severe vomiting, and diarrhea, runny nose, alerted mental status, loss of appetite and fever with recurrent urinary tract infection (UTI). But with no past surgical history.

\subsection{Clinical Findings and Diagnostic assessment}

Subsequently, the patient's temperature was $39,1^{\circ} \mathrm{C}$ normal range $\left(35.5^{\circ} \mathrm{C}\right.$ to $\left.37.5^{\circ} \mathrm{C}\right)$, Blood pressure (BP) was $90 / 58 \mathrm{mmHg}$ (hypotension), normal range $(120 / 80 \mathrm{mmHg}$ ), respiratory rate was $13 / \mathrm{min}$, pulse rate $115 \mathrm{bpm}$, and patient oxygen saturation (SPO2) was \% 95 at rest without oxygen. The murphy sign was negative.

Furthermore, laboratory test results showed elevated leucocytes $23.7 \times 10^{9} / \mathrm{I}$ (normal range 3.5-9.5 $\times$ $10^{9} / \mathrm{l}$ ), lymphocyte $12.8 \times 10^{9} / \mathrm{I}$ (normal range 1.1-3.2 $\times 10^{9} / \mathrm{I}$ ), granulocyte $20.2 \times 10^{9} / \mathrm{I}$ (normal range $\left.1.1-8.1 \times 10^{9} / \mathrm{l}\right)$, blood platelet $398 \times 10^{9} / \mathrm{I}$ (normal range 125-350 $\left.\times 10^{9} / \mathrm{l}\right)$, neutrophils $3.58 \times 10^{9} / \mathrm{I}$ (normal range 1.8-6.3 $\times 10^{9} / \mathrm{I}$, red blood cells (RBC) $4.54 \times 10^{12} / \mathrm{l}$ ) (normal range 125-350 $\times 10^{12} / \mathrm{I}$ ) and C-reactive protein $101 \mathrm{mg} / \mathrm{dl}$ (normal range $0.00-0.60 \mathrm{mg} / \mathrm{dl}$ ). In addition, the liver function test revealed that alkaline phosphate (ALP) $170 \mathrm{Lu} / \mathrm{L}$ normal range for male $(40-130 \mathrm{Lu} / \mathrm{L})$ and for female is $(32-$ $92 \mathrm{Lu} / \mathrm{L}$ ), S.G.O.T(AST) 23Lu/L (normal range 7- 46 Lu/L), S.G.P.T (ALT) $11 \mathrm{Lu} / \mathrm{L}$ (normal range7 - 49 $\mathrm{Lu} / \mathrm{L}$ ), serum amylase was $45 \mathrm{U} / \mathrm{dl}$ (normal range $25-125 \mathrm{U} / \mathrm{dl}$ ), serum lipase was $25 \mathrm{U} / \mathrm{dl}$ (normal range 13- $42 \mathrm{U} / \mathrm{dl}$ ) , serum total bilirubin was $0.2 \mathrm{mg} / \mathrm{dl}$ (normal range $0.3-1.2 \mathrm{mg} / \mathrm{dl}$ ). The patient was negative para influenza viruses, respiratory adenovirus, and syncytial virus. In addition, on July 21 , 2021 the patient was diagnosed with COVID-19 delta variant B.1.617.2 by RT-PCR, and genomic sequencing.

\subsection{Therapeutic Intervention}

On July 17, 2021, a 6-year-old female immediately administer Glucose saline $4 \%$ for 3 days, ceftriaxone vial $1 \mathrm{mg}$ every 12 hours for 6 days duration, acetaminophen bottle on the need to prevent fever followed by Flagyl bottle for every 24 hours for 3 days duration. On July,18, 20201, the patient had severe diarrhea 30 times per day, with a fully runny nose. On July 20,2021 , the patient was referred to the radiologist for further examination. The ultrasound of abdominal and pelvic was performed revealed normal liver in size, shape, and echogenicity, normal spleen and pancreas, normal both kidneys in shape, size, and echogenicity with acceptable cortical thickness, no stone, hydronephrosis, hydroureter and normal urinary bladder.no fluid-filled in bowel loops and no features of appendicitis apart from multiple stones each around 2-4 mm gall bladder related intravenous injection, such as ceftriaxone (Figure 1). However, the general urine examination was within normal limits. On July 23, 2021, the first author stopped the ceftriaxone vial due to side effects for children, such as cholelithiasis. On July 24, 2021, the patient feels 
better and removed the cannula. Three days later, the patient's RT-PCR was negative, and was discharged from the hospital.

\subsection{Follow Up}

The patient was discharged for outpatient monitoring.

\section{Discussion}

The literature confirmed that COVID-19 has numerous variants globally. The new delta variant B.1.617.2 rapidly spearing worldwide. Previously, the delta variant was detected in India, followed by the United Kingdom and the United States. B.1.617.2 bears spike mutations G142D, T19R, F157del, E156G, R158del, L452R, D614G, P681R, T478K, and D950N relative to Wuhan-1 D614G 118 [24]. The main strength of our case did not travel history to countries with a high prevalence of delta variant B.1.617.2. Clinical features of our case are (headache, sore throat, fever, runny nose, vomiting, diarrhea, loss of appetite, altered mental status. The laboratory findings of our case revealed that (elevated leucocytes WBC, granulocytes, lymphocytes, and blood platelets). Regarding the liver function test only elevated alkaline phosphate may be related to intravenous injection, such as ceftriaxone. However, significantly, only $6.5 \%$ of all COVID-19 cases occurred in fully immunized people, relatively few of these cases required admission to hospital [25]. In contrast, our case did not get the COVID-19 vaccine. In Iraq, there is a considerable lack of information about patients with COVID-19 caused by the delta variant compared to previous variants. However, the delta variant B.1.617.2 became globally [26]. Currently, there is no published research in Iraq about this variant. A recent study revealed that the estimated vaccine effectiveness against delta variant was approximately $88 \%$ with two doses of the BNT162b2 vaccine and approximately $67 \%$ with two doses of the ChAdOx $1 \mathrm{nCoV}-19$ vaccine [27]. In another study found the effectiveness of the Pfizer vaccine was 79\% (75-82) infected cases with delta variant concern (VOC), while the AstraZeneca vaccine, its effectiveness, approximately 60\% (53-66) [28]. Moreover, Iraq has limited devices and preventive measures against this variant; for this reason, we suggest vaccination, wearing masks, social distancing, and lockdown[29,30] are the great challenges to reduce the impact of the delta variant B.1.617.2. the limitation of our study is only one case; therefore, a large sample size is required to established clinical features and laboratory findings of the B.1.617.2 delta variant concern (VOC) in Iraq. our case may be an early signal for delta variant expansion. Further study is required to know the variants of this virus in Iraq.

\section{Conclusion}

Vaccination and preventing the spread of the virus and against it are important preventive approaches of delta variant. Sore throat, runny nose, headache, vomiting, diarrhea are major clinical features of the delta variant. Followed by elevation of leucocytes WBC, and blood platelets. To reduce the impact of new delta variant B.1.617.2 infection; hand washing, wearing the double mask, avoiding crowded and closed settings, social distancing, lockdown, and ensure good ventilation are major significant options against 
this variant. Therefore, fully vaccinated people should wear the mask and practice COVID-19 preventive strategies.

\section{Declarations}

\section{Declaration of Competing interests}

The authors declare that they have no known competing financial interests or personal relationships that could have appeared to influence the work reported in this paper.

\section{Funding}

This research did not receive any specific grant from funding agencies in the public, commercial, or notfor-profit sectors.

\section{Ethical Approval}

Ethical approval has been given by the ethics committee of Rania Medical City (RMC).

\section{Consent}

Written informed consent was obtained from the parents of this patient for publication of this case report and accompanying images. A copy of the written consent is available for review by the Editor-in-Chief of this journal on request.

\section{Provenance and peer review}

Not commissioned, externally peer-reviewed

\section{Acknowledgment}

Not applicable

\section{References}

[1] R.S. Baric, Emergence of a highly fit SARS-CoV-2 variant, N. Engl. J. Med. 383 (2020) 2684-2686.

[2] N. Chen, M. Zhou, X. Dong, J. Qu, F. Gong, Y. Han, Y. Qiu, J. Wang, Y. Liu, Y. Wei, Epidemiological and clinical characteristics of 99 cases of 2019 novel coronavirus pneumonia in Wuhan, China: a descriptive study, Lancet. 395 (2020) 507-513.

[3] R. Challen, L. Dyson, C.E. Overton, L.M. Guzman-Rincon, E.M. Hill, H.B. Stage, E. Brooks-Pollock, L. Pellis, F. Scarabel, D.J. Pascall, Early epidemiological signatures of novel SARS-CoV-2 variants: establishment of B. 1.617. 2 in England, MedRxiv. (2021). 
[4] E.C. Wall, M. Wu, R. Harvey, G. Kelly, S. Warchal, C. Sawyer, R. Daniels, P. Hobson, E. Hatipoglu, Y. Ngai, Neutralising antibody activity against SARS-CoV-2 VOCs B. 1.617. 2 and B. 1.351 by BNT162b2 vaccination, Lancet. 397 (2021) 2331-2333.

[5] K. Ito, C. Piantham, H. Nishiura, Predicted dominance of variant Delta of SARS-CoV-2 before Tokyo Olympic Games, Japan, July 2021, Eurosurveillance. 26 (2021) 2100570.

[6] S. Alizon, S. Haim-Boukobza, V. Foulongne, L. Verdurme, S. Trombert-Paolantoni, E. Lecorche, B. Roquebert, M.T. Sofonea, Rapid spread of the SARS-CoV-2 Delta variant in some French regions, June 2021, Eurosurveillance. 26 (2021) 2100573.

[7] B. Lovelace, "WHO Says Delta Is Becoming the Dominant Covid Variant Globally.," CNBC. (2021). https://www.cnbc.com/2021/06/18/who-says-delta-is-becoming-the-dominant-covid-variantglobally.html (accessed June 27, 2021).

[8] R. Sah, A.P. Khatiwada, S. Shrestha, K.C. Bhuvan, R. Tiwari, R.K. Mohapatra, K. Dhama, A.J. Rodriguez-Morales, COVID-19 vaccination campaign in Nepal, emerging UK variant and futuristic vaccination strategies to combat the ongoing pandemic, Travel Med. Infect. Dis. 41 (2021) 102037.

[9] P. Schlagenhauf, D. Patel, A. Rodriguez-Morales, P. Gautret, M.P. Grobusch, K. Leder, Variants, vaccines and vaccination passports: Challenges and chances for travel medicine in 2021, Travel Med. Infect. Dis. (2021).

[10] J.H. Beigel, K.M. Tomashek, L.E. Dodd, A.K. Mehta, B.S. Zingman, A.C. Kalil, E. Hohmann, H.Y. Chu, A. Luetkemeyer, S. Kline, Remdesivir for the treatment of Covid-19-preliminary report, N. Engl. J. Med. (2020).

[11] J.D. Goldman, D.C.B. Lye, D.S. Hui, K.M. Marks, R. Bruno, R. Montejano, C.D. Spinner, M. Galli, M.-Y. Ahn, R.G. Nahass, Remdesivir for 5 or 10 days in patients with severe Covid-19, N. Engl. J. Med. 383 (2020) 1827-1837.

[12] C.D. Spinner, R.L. Gottlieb, G.J. Criner, J.R.A. López, A.M. Cattelan, A.S. Viladomiu, O. Ogbuagu, P. Malhotra, K.M. Mullane, A. Castagna, Effect of remdesivir vs standard care on clinical status at 11 days in patients with moderate COVID-19: a randomized clinical trial, Jama. 324 (2020) 1048-1057.

[13] A.B. Cavalcanti, F.G. Zampieri, R.G. Rosa, L.C.P. Azevedo, V.C. Veiga, A. Avezum, L.P. Damiani, A. Marcadenti, L. Kawano-Dourado, T. Lisboa, Hydroxychloroquine with or without azithromycin in mild-tomoderate Covid-19, N. Engl. J. Med. 383 (2020) 2041-2052.

[14] J.A.C. Sterne, S. Murthy, J. V Diaz, A.S. Slutsky, J. Villar, D.C. Angus, D. Annane, L.C.P. Azevedo, O. Berwanger, A.B. Cavalcanti, Association between administration of systemic corticosteroids and mortality among critically ill patients with COVID-19: a meta-analysis, Jama. 324 (2020) 1330-1341. 
[15] M.J. Joyner, J.W. Senefeld, S.A. Klassen, J.R. Mills, P.W. Johnson, E.S. Theel, C.C. Wiggins, K.A. Bruno, A.M. Klompas, E.R. Lesser, Effect of convalescent plasma on mortality among hospitalized patients with COVID-19: initial three-month experience, Medrxiv. (2020).

[16] L. Li, W. Zhang, Y. Hu, X. Tong, S. Zheng, J. Yang, Y. Kong, L. Ren, Q. Wei, H. Mei, Effect of convalescent plasma therapy on time to clinical improvement in patients with severe and life-threatening COVID-19: a randomized clinical trial, Jama. 324 (2020) 460-470.

[17] J.T. Sims, V. Krishnan, C.-Y. Chang, S.M. Engle, G. Casalini, G.H. Rodgers, N. Bivi, B.J. Nickoloff, R.J. Konrad, S. de Bono, Characterization of the cytokine storm reflects hyperinflammatory endothelial dysfunction in COVID-19, J. Allergy Clin. Immunol. 147 (2021) 107-111.

[18] V. Bronte, S. Ugel, E. Tinazzi, A. Vella, F. De Sanctis, S. Canè, V. Batani, R. Trovato, A. Fiore, V. Petrova, Baricitinib restrains the immune dysregulation in COVID-19 patients, MedRxiv. (2020).

[19] J. Stebbing, V. Krishnan, S. de Bono, S. Ottaviani, G. Casalini, P.J. Richardson, V. Monteil, V.M. Lauschke, A. Mirazimi, S. Youhanna, Mechanism of baricitinib supports artificial intelligence-predicted testing in COVID-19 patients, EMBO Mol. Med. 12 (2020) e12697.

[20] F. Dastan, A. Saffaei, S. Haseli, M. Marjani, A. Moniri, Z. Abtahian, A. Abedini, A. Kiani, S. Seifi, H. Jammati, Promising effects of tocilizumab in COVID-19: a non-controlled, prospective clinical trial, Int. Immunopharmacol. 88 (2020) 106869.

[21] R.B. Malabadi, N.T. Meti, R.K. Chalannavar, Role of herbal medicine for controlling coronavirus (SARS-CoV-2) disease (COVID-19), Int. J. Res. Sci. Innov. 8 (2021) 135-165.

[22] V. Shinde, S. Bhikha, Z. Hoosain, M. Archary, Q. Bhorat, L. Fairlie, U. Lalloo, M.S.L. Masilela, D. Moodley, S. Hanley, Efficacy of NVX-CoV2373 Covid-19 Vaccine against the B. 1.351 Variant, N. Engl. J. Med. 384 (2021) 1899-1909.

[23] R.A. Agha, T. Franchi, C. Sohrabi, G. Mathew, A. Kerwan, A. Thoma, A.J. Beamish, A. Noureldin, A. Rao, B. Vasudevan, The SCARE 2020 guideline: updating consensus Surgical CAse REport (SCARE) guidelines, Int. J. Surg. 84 (2020) 226-230.

[24] P. Mlcochova, S. Kemp, M.S. Dhar, G. Papa, B. Meng, S. Mishra, C. Whittaker, T. Mellan, I. Ferreira, R. Datir, SARS-CoV-2 B. 1.617. 2 Delta variant emergence, replication and sensitivity to 1 neutralising antibodies 2, Biorxiv. (2021). https://www.biorxiv.org/content/10.1101/2021.05.08.443253v4.

[25] J.M. Musser, P.A. Christensen, R.J. Olsen, S.W. Long, S. Subedi, J.J. Davis, P. Hodjat, D.R. Walley, J.C. Kinskey, J.D. Gollihar, Delta variants of SARS-CoV-2 cause significantly increased vaccine breakthrough COVID-19 cases in Houston, Texas, MedRxiv. (2021).

[26] P. Chen, A. Nirula, B. Heller, R.L. Gottlieb, J. Boscia, J. Morris, G. Huhn, J. Cardona, B. Mocherla, V. Stosor, SARS-CoV-2 neutralizing antibody LY-CoV555 in outpatients with Covid-19, N. Engl. J. Med. 384 
[27] J. Lopez Bernal, N. Andrews, C. Gower, E. Gallagher, R. Simmons, S. Thelwall, J. Stowe, E. Tessier, N. Groves, G. Dabrera, Effectiveness of Covid-19 vaccines against the B. 1.617. 2 (delta) variant, N. Engl. J. Med. (2021).

[28] A. Sheikh, J. McMenamin, B. Taylor, C. Robertson, SARS-CoV-2 Delta VOC in Scotland: demographics, risk of hospital admission, and vaccine effectiveness, Lancet. (2021).

[29] P.W. Clapp, E.E. Sickbert-Bennett, J.M. Samet, J. Berntsen, K.L. Zeman, D.J. Anderson, D.J. Weber, W.D. Bennett, Evaluation of cloth masks and modified procedure masks as personal protective equipment for the public during the COVID-19 pandemic, JAMA Intern. Med. 181 (2021) 463-469.

[30] J.G. Allen, A.M. Ibrahim, Indoor Air Changes and Potential Implications for SARS-CoV-2 Transmission, JAMA. 325 (2021) 2112-2113.

\section{Figures}

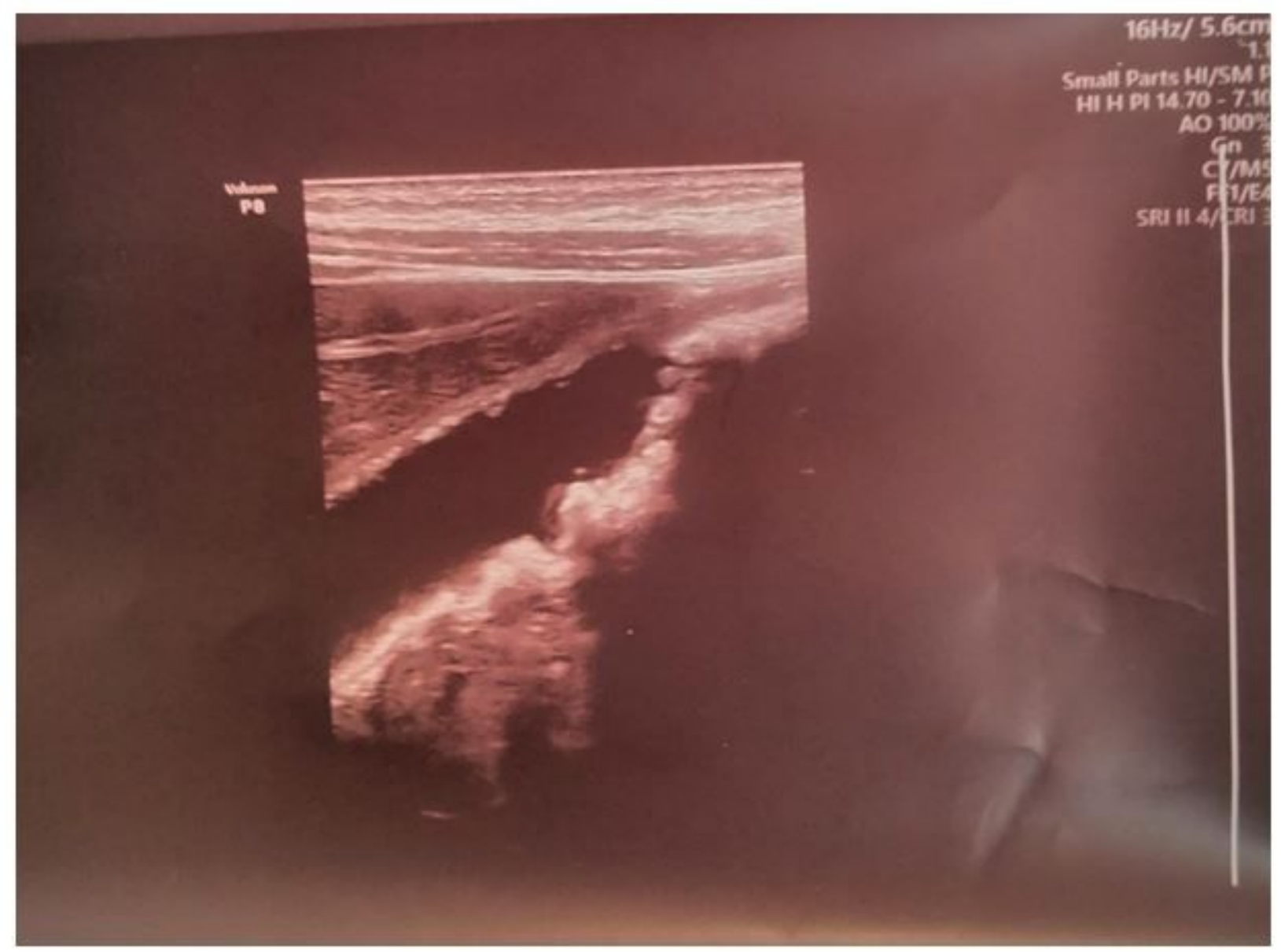

Figure 1 
Multiple stones each around 2-4 mm gall bladder relates intravenous injection, such as ceftriaxone.

\section{Supplementary Files}

This is a list of supplementary files associated with this preprint. Click to download.

- SCARE2020.docx 